\title{
Streaming Android Terintegrasi dengan Sensor PIR sebagai Sensor Gerak
}

\author{
Adila Khoirunnisa, Sumantri K. Risandriya, dan Heru Wijanarko* \\ Politeknik Negeri Batam, Batam, Indonesia \\ *Email: wijanarko@polibatam.ac.id
}

\begin{abstract}
Abstrak-Streaming merupakan proses pengiriman data secara berkelanjutan yang memungkinkan pengguna mengakses file yang belum diterima secara keseluruhan. Metode streaming dapat diaplikasikan di kehidupan sehari-sehari untuk memantau aktivitas yang sedang berlangsung salah satu contohnya adalah aktivitas di luar pintu. Aktivitas ini dapat bersifat negatif maupun positif. Berdasarkan permasalahan tersebut, penulis merancang sistem pendeteksian aktivitas dengan menggunakan Passive Infrared Sensor (PIR) yang akan mendeteksi pergerakan dari tubuh manusia. Dengan begitu, sensor PIR dapat menjadi bel rumah otomatis apabila ada orang yang berkunjung. Setelah sensor PIR mendeteksi, maka kamera Android (client) akan aktif dan mengirim pergerakan yang sedang berlangsung ke Android (user) agar pemilik rumah dapat memantau secara langsung. Hasil dari penelitian ini menyimpukan layanan video streaming dengan menggunakan protokol TCP telah memenuhi standar dari Quality of Services (QoS) TIPHON dengan menggunakan parameter delay 3,95745 ms dengan kategori sangat memuaskan, parameter throughput 327637,144 bit per second (bps) dengan kategori sangat memuaskan, serta parameter packet loss $0,952 \%$ dengan kategori memuaskan. Berdasarkan penelitian yang telah dilakukan, penulis berharap alat ini dapat membantu pemilik rumah dalam memantau aktivitas yang ada di luar pintu dari mana saja.
\end{abstract}

Kata Kunci : Streaming, Android, sensor PIR

\section{Pendahuluan}

Streaming merupakan proses pengiriman data secara berkelanjutan yang memungkinkan pengguna mengakses file yang belum diterima secara keseluruhan. Jika dilihat dari kegunaannya, streaming dapat digunakan di kehidupan seharisehari untuk memantau suatu kejadian maupun aktivitas yang sedang berlangsung saat itu.

Aktivitas yang dilakukan di luar pintu dapat bersifat negatif maupun positif. Kegiatan bertamu ataupun berkunjung temasuk kedalam kegiatan yang bersifat positif dan aktivitas yang bersifat negatif salah satu contohnya adalah tindak kejahatan pencurian. Untuk itu dibutuhkan suatu sistem yang mampu untuk mendeteksi semua kegiatan yang sedang terjadi, baik itu kegiatan bertamu ataupun kegiatan yang tidak diinginkan.
Teknologi yang pernah dibuat untuk sistem keamana dan monitoring di antaranya adalah Closed Circuit Television (CCTV) dengan memanfaatkan kamera CCTV dan smartphone untuk melakukan monitoring sebuah ruangan [1], monitoring tempat penitipan anak [2], dan mengontrol smart home berbasis Internet of Things (IoT) [3]. Mirip dengan sistem keamanan dengan konsep CCTV, sebuah sistem yang lebih sederhana dan dapat diakses dari mana saja ditawarkan oleh penulis, yaitu sebuah sistem streaming Android yang terintegrasi dengan sebuah sensor PIR untuk mendeteksi adanya pergerakan dan menjadi trigger mengirimkan notifikasi ke pemilik rumah.

Sistem ini dapat digunakan untuk mendeteksi adanya aktivitas karena adanya perubahan panas dari objek. Sesuai dengan namanya 'Passive', sensor ini hanya merespon energi dari pancaran sinar infrared pasif yang dimiliki oleh setiap benda yang terdeteksi olehnya. Benda yang dapat dideteksi oleh sensor ini biasanya adalah tubuh manusia, dengan begitu sensor PIR dapat menjadi bel rumah otomatis apabila ada orang yang berkunjung, tanpa harus menunggu tamu tersebut menekan bel rumah atau berusaha untuk membuka-tutup pintu. Selain untuk mendeteksi, dibutuhkan juga sistem operasi untuk menampilkan hasil dari pendekteksian aktivitas dengan tujuan untuk mempermudah dalam pemantauan. Sistem operasi bersifat open source sehingga mempermudah pengguna untuk memodifikasi dan melakukan pengembangan. Penelitian ini diharapkan dapat menjadi alternatif dalam memantau aktivitas yang ada di luar pintu dari berbagai lokasi dengan menggunakan streaming sebagai penghatar data dan sensor PIR sebagai bel otomatis ketika sedang terjadi pergerakan orang di luar pintu.

\section{Metode}

\section{A. Perancangan Sistem}

Sistem ini menggunakan desain diagram alir yang ditunjukkan pada Gambar 1 untuk memberikan gambaran yang jelas terhadap alat dan sistem yang dibuat. 


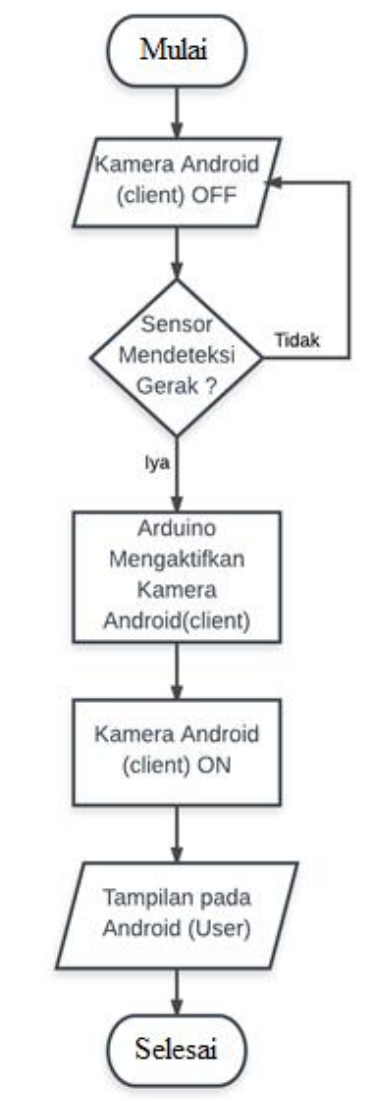

Gambar 1. Diagram alir sistem

Pada langkah awal, kamera pada Android (client) berada pada posisi off. Ketika sensor PIR mendeteksi adanya gerakan, maka perubahan gerakan tersebut akan diterima oleh arduino (mikrokontroler). Setelah data diterima, maka arduino akan mengaktifkan kamera pada Android (client) sehingga kamera pada Android (client) tersebut dalam posisi on untuk menampilkan aktivitas yang sedang terjadi di luar pintu dan mengirim gambar ke Android (user) serta menampilkan secara real time atau secara streaming.

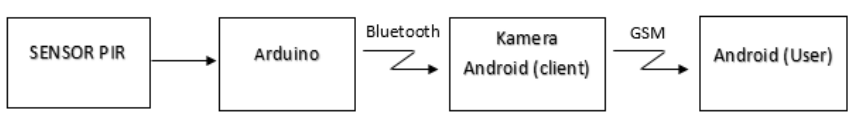

Gambar 2. Diagram blok alat

Desain blok diagram ditunjukkan pada Gambar 2. Komponen yang digunakan antara lain adalah sensor PIR yang digunakan sebagai input dari sistem, Arduino digunakan untuk memroses data yang didapat oleh sensor dan langsung mengaktifkan kamera pada Android (client), dan Android (user) sebagai penampil hasil gambar yang telah diterima oleh kamera secara live streaming.

\section{B. Parameter $Q o S$}

Video streaming adalah kompresi dari susunan gambar bergerak yang dikirimkan melalui jaringan internet dan dapat diputar oleh pengguna saat ia menginginkannya [4]. Proses pengiriman file data saat streaming harus dilakukan secara konstan agar video yang diterima oleh pengguna tidak ada yang hilang. Ada beberapa faktor yang harus diperhatikan untuk perancangan sistem dan jaringannya, salah satunya adalah bandwidth. Bandwidth merupakan jumlah bit-bit informasi yang dapat mengalir melewati sebuah koneksi jaringan dalam periode tertentu.

Untuk melihat seberapa handal sistem perancangan yang dibuat, parameter lain yang diukur adalah waktu tunda (delay). Waktu tunda pada saat proses pertukaran data berupa paketpaket bervariasi dan berfluktuasi. Variasi dalam waktu tunda ini dapat dicari menggunakan (1) dan (2):

$$
\begin{gathered}
\text { Delay }=\frac{\text { Packet Length }}{\text { Link Bandwidth }} \\
\text { Jitter }=\frac{\text { Total variasi delay }}{\text { Total paket yang diterima }}
\end{gathered}
$$

Pada saat pengiriman data end-to-end terdapat kemungkinan paket yang hilang atau terhapus, yang disebut dengan packet loss. Dimana pada jaringan nirkabel dapat saja diwakili oleh bit errors atau burst errors. Lost rate ini dapat dihitung menggunakan (3):

$$
\text { Packet_Loss }=\frac{(\text { Paket_dikirim }- \text { Paket_diterima) })}{\text { Paket_dikirim }} \times 100 \%
$$

\section{Passive Infrared Sensor (PIR)}

Pada riset ini, PIR digunakan sebagai sensor untuk mendeteksi adanya perubahan panas yang diterima dari pergerakan manusia yang berada di depan pintu. Penggunaan PIR sendiri sudah pernah diaplikasikan pada beberapa riset sebelumnya seperti, sistem keamanan laboratorium [5], rumah [6], dan kerambah ikan [7]. Sensor PIR dapat diatur area jangkauannya menyesuaikan kebutuhan, akan tetapi jarak maksimalnya hanya sebesar kurang lebih $10 \mathrm{~m}$, tergantung dari posisi sensor. Pada riset ini, PIR dipasang dengan metode wall mount.

\section{HASIL DAN PEMBAHASAN}

\section{A. Pengujian Sensor PIR}

Pengujian sensor PIR ini dilakukan di luar ruangan atau di depan pintu. Pengujian sensor PIR ini dilakukan dengan mengatur sensitivitas dari sensor. Putaran yang dilakukan dengan satuan derajat, di mana putaran minimum yang dapat dilakukan adalah $0^{\circ}-180^{\circ}$. Penulis melakukan tiga kali pengambilan data dengan nilai derajat dari $45^{\circ}, 90^{\circ}$ dan $135^{\circ}$. Pemasangan sensor PIR dapat dilihat pada Gambar 3. Hasil dari pengujian sensor dengan putaran sensitivitas $45^{\circ}, 90^{\circ}$ dan $135^{\circ}$ dapat dilihat pada Tabel I, II, dan III. 


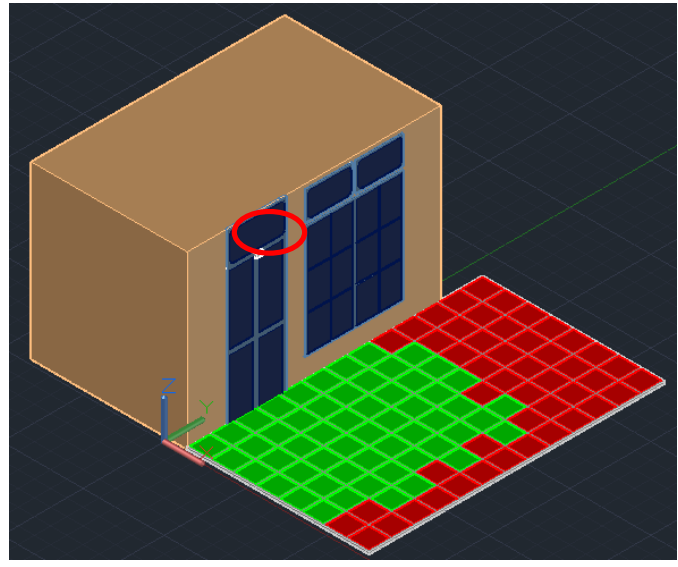

Gambar 3. Simulasi pengujian sensor PIR

TABEL I

PENGUJIAN SENSOR PIR DENGAN PUTARAN SENSITIVITAS $45^{0}$

\begin{tabular}{|c|c|c|c|c|c|c|c|c|}
\hline $\begin{array}{c}\text { EEBAR } \\
\text { PANJANG }\end{array}$ & $0.3 \mathrm{~m}$ & $0.6 \mathrm{~m}$ & $0.9 \mathrm{~m}$ & $1.2 \mathrm{~m}$ & $1.5 \mathrm{~m}$ & $1.8 \mathrm{~m}$ & $2.1 \mathrm{~m}$ & $2.4 \mathrm{~m}$ \\
\hline $0.3 \mathrm{~m}$ & NOT OK & NOT OK & NOT OK & NOT OK & NOT OK & NOT OK & NOT OK & NOT OK \\
\hline $0.6 \mathrm{~m}$ & NOT OK & NOT OK & NOT OK & NOT OK & NOT OK & NOT OK & NOT OK & NOT OK \\
\hline $0.9 \mathrm{~m}$ & NOT OK & NOT OK & NOT OK & NOT OK & NOT OK & NOT OK & NOT OK & NOT OK \\
\hline $1.2 \mathrm{~m}$ & NOT OK & NOT OK & NOT OK & NOT OK & NOT OK & NOT OK & NOT OK & NOT OK \\
\hline $1.5 \mathrm{~m}$ & NOT OK & OK & OK & OK & NOT OK & OK & NOT OK & NOT OK \\
\hline $1.8 \mathrm{~m}$ & OK & OK & OK & OK & OK & OK & OK & NOT OK \\
\hline $2.1 \mathrm{~m}$ & OK & OK & OK & OK & OK & OK & NOT OK & NOT OK \\
\hline $2.4 \mathrm{~m}$ & OK & OK & OK & OK & OK & OK & OK & NOT OK \\
\hline $2.7 \mathrm{~m}$ & OK & OK & OK & OK & OK & OK & NOT OK & NOT OK \\
\hline $3 \mathrm{~m}$ & OK & OK & OK & OK & OK & OK & OK & NOT OK \\
\hline $3.3 \mathrm{~m}$ & OK & OK & OK & OK & OK & OK & OK & NOT OK \\
\hline $3.6 \mathrm{~m}$ & OK & OK & OK & OK & OK & OK & NOT OK & NOT OK \\
\hline $3.9 \mathrm{~m}$ & OK & OK & OK & OK & OK & OK & NOT OK & NOT OK \\
\hline
\end{tabular}

TABEL II

PENGUJIAN SENSOR PIR DENGAN PUTARAN SENSITIVITAS $90^{\circ}$

\begin{tabular}{|c|c|c|c|c|c|c|c|c|}
\hline $\begin{array}{c}\text { CEBAR } \\
\text { PANJANG }\end{array}$ & $0.3 \mathrm{~m}$ & $0.6 \mathrm{~m}$ & $0.9 \mathrm{~m}$ & $1.2 \mathrm{~m}$ & $1.5 \mathrm{~m}$ & $1.8 \mathrm{~m}$ & $2.1 \mathrm{~m}$ & $2.4 \mathrm{~m}$ \\
\hline $0.3 \mathrm{~m}$ & OK & NOT OK & NOT OK & NOT OK & OK & NOT OK & NOT OK & NOT OK \\
\hline $0.6 \mathrm{~m}$ & NOT OK & OK & OK & NOT OK & NOT OK & OK & NOT OK & NOT OK \\
\hline $0.9 \mathrm{~m}$ & OK & NOT OK & NOT OK & OK & NOT OK & NOT OK & OK & NOT OK \\
\hline $1.2 \mathrm{~m}$ & NOT OK & OK & OK & NOT OK & OK & OK & NOT OK & OK \\
\hline $1.5 \mathrm{~m}$ & OK & OK & OK & OK & OK & OK & NOT OK & NOT OK \\
\hline $1.8 \mathrm{~m}$ & OK & OK & OK & OK & OK & OK & OK & OK \\
\hline $2.1 \mathrm{~m}$ & OK & OK & OK & OK & OK & OK & OK & OK \\
\hline $2.4 \mathrm{~m}$ & OK & OK & OK & OK & OK & OK & OK & OK \\
\hline $2.7 \mathrm{~m}$ & OK & OK & OK & OK & OK & OK & OK & OK \\
\hline $3 \mathrm{~m}$ & OK & OK & OK & OK & OK & OK & OK & OK \\
\hline $3.3 \mathrm{~m}$ & OK & OK & OK & OK & OK & OK & OK & OK \\
\hline $3.6 \mathrm{~m}$ & OK & OK & OK & OK & OK & OK & OK & OK \\
\hline $3.9 \mathrm{~m}$ & OK & OK & OK & OK & OK & OK & OK & OK \\
\hline
\end{tabular}

TABEL III

PENGUJIAN SENSOR PIR DENGAN PUTARAN SENSITIVITAS $135^{\circ}$

\begin{tabular}{|c|c|c|c|c|c|c|c|c|}
\hline $\begin{array}{c}\text { GEBAR } \\
\text { PANJANG }\end{array}$ & $0.3 \mathrm{~m}$ & $0.6 \mathrm{~m}$ & $0.9 \mathrm{~m}$ & $1.2 \mathrm{~m}$ & $1.5 \mathrm{~m}$ & $1.8 \mathrm{~m}$ & $2.1 \mathrm{~m}$ & $2.4 \mathrm{~m}$ \\
\hline $0.3 \mathrm{~m}$ & $\mathrm{OK}$ & $\mathrm{OK}$ & $\mathrm{OK}$ & $\mathrm{OK}$ & $\mathrm{OK}$ & $\mathrm{OK}$ & $\mathrm{OK}$ & $\mathrm{OK}$ \\
\hline $0.6 \mathrm{~m}$ & OK & OK & OK & OK & OK & OK & OK & OK \\
\hline $0.9 \mathrm{~m}$ & OK & OK & OK & OK & OK & OK & OK & OK \\
\hline $1.2 \mathrm{~m}$ & OK & OK & OK & OK & OK & OK & OK & OK \\
\hline $1.5 \mathrm{~m}$ & OK & OK & OK & OK & OK & OK & OK & OK \\
\hline $1.8 \mathrm{~m}$ & OK & OK & OK & OK & OK & OK & OK & OK \\
\hline $2.1 \mathrm{~m}$ & OK & OK & OK & OK & OK & OK & OK & OK \\
\hline $2.4 \mathrm{~m}$ & OK & OK & OK & OK & OK & OK & OK & OK \\
\hline $2.7 \mathrm{~m}$ & OK & OK & OK & OK & OK & OK & OK & OK \\
\hline $3 \mathrm{~m}$ & OK & OK & OK & OK & OK & OK & OK & OK \\
\hline $3.3 \mathrm{~m}$ & OK & OK & OK & OK & OK & OK & OK & OK \\
\hline $3.6 \mathrm{~m}$ & OK & OK & OK & OK & OK & OK & OK & OK \\
\hline $3.9 \mathrm{~m}$ & OK & OK & OK & OK & OK & OK & OK & OK \\
\hline
\end{tabular}

Berdasarkan Gambar 3, lingkaran merah merupakan peletakan sensor PIR di rumah. Ukuran panjang lebar yang digunakan merupakan ukuran area dari lantai. Penulis melakukan pengujian pada masing-masing area lantai. Hasil pengujian sensor yang ditandai dengan warna hijau berarti OK (dapat terdeteksi oleh sensor), sedangkan warna merah berarti NOT OK (tidak dapat terdeteksi oleh sensor).

Berdasarkan Tabel I, II, dan III, pengujian pendeteksian objek dengan mengatur putaran sensitivitas di nilai $45^{\circ}, 90^{\circ}$ dan $135^{\circ}$ dapat dilihat tingkat keberhasilannya sebagai berikut:

$$
\begin{aligned}
\text { Persentase keberhasilan }= & \frac{\text { Jumlah Keberhasilan }}{\text { Jumlah Percobaan }} \times 100 \% \\
& =\frac{56}{104} \times 100 \%=53,84 \% \\
& =\frac{83}{104} \times 100 \%=79,80 \% \\
& =\frac{104}{104} \times 100 \%=100 \%
\end{aligned}
$$

Dengan mengatur sensitivitas dari sensor PIR, dapat dihasilkan pendeteksian objek yang berbeda. Pengujian ini dilakukan dengan tiga skenario di mana pengujian pertama dengan mengatur putaran sensitivitas di nilai $45^{\circ}$ mendapat tingkat persentase keberhasilan 53.84\%. Skenario, kedua yaitu pengujian dengan mengatur dengan mengatur putaran sensitivitas di nilai $90^{\circ}$, mendapat tingkat persentase keberhasilan $79,80 \%$. Skenario ketiga, yaitu pengujian dengan mengatur putaran sensitivitas di nilai $135^{\circ}$, mendapat tingkat persentase keberhasilan 100\%. Dari hasil persentase keberhasilan, didapatkan bahwa dengan putaran sensitivitas kurang dari $135^{\circ}$ menandakan daerah yang tidak dapat dijangkau oleh sensor PIR. Hal ini dikarenakan kurangnya sensitivitas sensor PIR. Ini menunjukkan bahwa sensor dapat digunakan untuk sistem ini dengan terlebih dahulu diatur sensitivitasnya di nilai $135^{\circ}$ agar seluruh wilayah pengujian dapat mendeteksi objek dengan baik.

\section{B. Pengujian Pengiriman Data Android}

Pengujian ini dilakukan untuk mengetahui kehandalan dari aplikasi yang telah dibuat. Pengujian ini dilakukan di dua smartphone Android dengan jaringan 4G. Untuk menguji pengiriman data streaming serta kemampuan jaringan dalam menangani traffic yang ada serta kemampuan jaringan untuk menyediakan layanan yang lebih baik sehingga penulis menggunakan parameter dari Quality Of Service (QoS). Parameter yang akan dicapture melalui Wireshark untuk pengiriman data ini adalah sebagai berikut:

\section{1) Delay (Waktu Tunda)}

Pengambilan data ini mengunakan Wireshark pada laptop yang terkoneksi jaringan hotspot dari smartphone Android (user). Android (user) dinamakan Client2, sedangkan Android (client) dinamakan Client 1 . Pada Tabel IV terlihat bahwa ratarata delay pada saat proses pengiriman data dari Android (user) ke Android (client) adalah 0,00395745s. 
TABEL IV

DELAY CLIENT2 KE CLIENT1

\begin{tabular}{|c|c|c|}
\hline No & Detik Ke - & Client 2 menuju ke Client 1 (s) \\
\hline 1 & 10 ke 12 & 0.004964 \\
\hline 2 & 23 ke 25 & 0.003716 \\
\hline 3 & 26 ke 28 & 0.004783 \\
\hline 4 & 62 ke 64 & 0.00337 \\
\hline 5 & 65 ke 67 & 0.003669 \\
\hline 6 & 68 ke 70 & 0.004338 \\
\hline 7 & 125 ke 127 & 0.003932 \\
\hline 8 & 128 ke 130 & 0.00238 \\
\hline 9 & 131 ke 133 & 0.002644 \\
\hline 10 & 134 ke 136 & 0.003679 \\
\hline 11 & 137 ke 139 & 0.006058 \\
\hline \multicolumn{2}{|c|}{ Rata - Rata } & 0.003957545 \\
\hline
\end{tabular}

\section{2) Throughput}

Throughput adalah bandwith aktual yang terukur pada suatu ukuran waktu tertentu. Throughput merupakan jumlah bit yang berhasil dikirim pada suatu jaringan. Data ini dapat diambil langsung dari Wireshark pada tab summary berikut seperti yang tertera pada Gambar 4. Nilai untuk throughput dapat dilihat Avg.Mbit/sec, di mana hasil datanya adalah 0,328 Mbit/sec.

\begin{tabular}{|c|c|c|c|c|c|}
\hline Traffic & Captured 1 & Displayed 4 & Displayed \% 4 & Marked 1 & Marked \% \\
\hline Packets & 11344 & 11344 & $100.000 \%$ & 0 & $0.000 \%$ \\
\hline \multicolumn{6}{|c|}{ Between first and last packet $235.955 \mathrm{sec}$} \\
\hline Avg. packets/sec & 48.077 & & & & \\
\hline Avg. packet size & 851.856 bytes & & & & \\
\hline Bytes & 9663453 & 9663453 & $100.000 \%$ & 0 & $0.000 \%$ \\
\hline Avg. bytes/sec & 40954.576 & & & & \\
\hline Avg. MBit/sec & 0.328 & & & & \\
\hline
\end{tabular}

Gambar 4. Tampilan summary pada Wireshark

\section{3) Packet Loss}

\begin{tabular}{|c|c|c|c|c|c|}
\hline Traffic & Captured 1 & Displayed 1 & Displayed \% 4 & Marked 1 & Marked \% ฯ \\
\hline Packets & 11344 & 11236 & $99.048 \%$ & 0 & $0.000 \%$ \\
\hline Between first and last packet & t $235.955 \mathrm{sec}$ & $235.955 \mathrm{sec}$ & & & \\
\hline Avg. packets/sec & 48.077 & 47.619 & & & \\
\hline Avg. packet size & 851.856 bytes & s 859.050 bytes & & & \\
\hline Bytes & 9663453 & 9652285 & $99.884 \%$ & 0 & $0.000 \%$ \\
\hline Avg. bytes/sec & 40954.576 & 40907.245 & & & \\
\hline Avg. MBit/sec & 0.328 & 0.327 & & & \\
\hline
\end{tabular}

Gambar 5. Tampilan summary hasil filter pada Wireshark

Packet loss merupakan kondisi yang menunjukkan jumlah total paket yang hilang pada jaringan. Data untuk packet loss dapat dilihat langsung dari Wireshark pada tab summary dengan mem-filter protokol jaringan yang digunakan untuk berkomunikasi. Protokol yang digunakan adalah protokol TCP. Data pada tab summary setelah data di-filter tertera pada Gambar 5.

Dari Gambar 5, untuk mencari packet loss digunakan perhitungan sebagai berikut:

$$
\text { Packet Loss }=\left(\frac{11344-11236}{11344}\right) \times 100 \%=0.952 \%
$$

Keterangan :

Paket data dikirim : Packet Data Captured

Paket data diterima : Packet Data Displayed

Berdasarkan hasil pengujian, parameter dari QoS yang pertama kali diuji yang adalah parameter delay. delay saat proses pengiriman data dari Android (user) ke Android (client) adalah 0,00395745 s. Delay ini apabila dimasukkan kedalam standar yang diambil dari TIPHON masuk kedalam kategori sangat bagus dengan indeks 4 untuk suatu pengiriman data dengan hasil konversi dalam satuan mili seconds yaitu 3,95745ms.

Parameter dari QoS selanjutnya yang diuji adalah throughput. Dari hasil pengujian antara throughput yang diperoleh dari Wireshark adalah $0.328 \mathrm{Mbit} / \mathrm{sec}$. Throughput ini termasuk kedalam kategori sangat bagus dengan indeks 4 sesuai dengan standar yang diambil dari TIPHON dengan hasil 327637,151 bps.

Parameter dari QoS selanjutnya yang diuji adalah Packet loss. Dari hasil perhitungan didapatkan bahwa persentase packet loss adalah $0,952 \%$. Dengan persentase packet loss yang didapat, hasil ini termasuk kedalam kategori bagus dengan indeks 3 sesuai dengan standar yang diambil dari TIPHON.

Dari ketiga parameter tersebut untuk mendapatkan nilai QoS yang diambil dari TIPHON sesuai dengan indeks dari masing-masing parameter dapat dilihat pada Tabel V. Berdasarkan tabel tersebut, dapat dilihat bahwa dari parameter yang telah diuji didapatkan hasil $\mathrm{QoS}$ atau layanan kualitas yang diberikan oleh sistem ini dari delay dengan kategori sangat memuaskan, throughput dengan parameter sangat memuaskan serta packet loss dengan kategori memuaskan.

TABEL V PENGUKURAN PARAMETER QOS

\begin{tabular}{|c|c|c|c|}
\hline \multirow{2}{*}{ Parameter } & \multirow{2}{*}{ Hasil Pengujian } & \multicolumn{2}{|c|}{ Keterangan } \\
\cline { 3 - 4 } Delay & $3.957 \mathrm{~ms}$ & 4 & $\begin{array}{c}\text { Sangat } \\
\text { memuaskan }\end{array}$ \\
\hline Throughput & $327637.144 \mathrm{bps}$ & 4 & $\begin{array}{c}\text { Sangat } \\
\text { memuaskan }\end{array}$ \\
\hline Packet loss & $0.95 \%$ & 3 & Memuaskan \\
\hline
\end{tabular}

\section{KesimpUlan}

Sistem yang telah dibuat dapat digunakan untuk memantau aktivitas di luar pintu menggunakan Android dengan dipicu oleh sensor PIR sebagai sensor gerak yang menggunakan metode streaming sehingga dapat memantau keadaan secara real time dan dapat diakses dari mana saja oleh pemilik rumah dengan koneksi internet. Pada layanan video streaming yang dilakukan dengan menggunakan protokol TCP dalam pengiriman data sudah memenuhi standar dari QoS dengan menggunakan parameter delay, throughput dan packet loss. Hasil yang dicapai adalah delay 3,95745 $\mathrm{ms}$ dengan kategori sangat bagus, throughput 327637,144 bps dengan kategori sangat bagus, serta nilai packet loss $0,952 \%$ dengan kategori bagus. Layanan delay yang dihasilkan masuk kategori sangat 
memuaskan, layanan throughput sangat memuaskan, dan layanan packet loss memuaskan.

\section{REFERENSI}

[1] Ahmadil Amin, "Monitoring Kamera CCTV Melalui PC dan Smartphone," EEICT, vol. 1, no. 2, pp. 11-20, 2018.

[2] Syahid, Sidiq Syamsul H, Ari Santoso, and Aji Hari Riyadi, "Rancang Bangun Sistem Monitoring Anak di Tempat Penitipan Anak Menggunakan Kamera CCTV Berbasis Android," in SENTRINOV, vol. 3, 2017, pp. 293-299.

[3] Rijal Permana, Rumani M., and Unang Sunarya, "Perancangan Sistem Keamanan dan Kontrol Smart Home Berbasis Internet of Things," , vol. 4, 2017, pp. 4015-4022.

[4] Adinandra S, "Kendali Robot Pemonitor Jarak Jauh Berbasis Smartphone Android Implementasi Sistem Dan Analisis Kualitas Video Streaming," in Seminar Nasional ke - 9: Rekayasa Teknologi Industri dan Informasi, Yogyakarta, 2015, pp. 161-166.

[5] Arif Supriyanto, "Rancang Bangun Sistem Keamanan Laboratorium TI Menggunakan Sensor Passive Infrared Berbasis Arduino," Jurnal Sains dan Informatika, vol. 3, no. 2, pp. 101-105, November 2017.

[6] Haribu Tempongbuka, Elia Kendek Allo, and Sherwin R. U. A. Sompie, "Rancang Bangun Sistem Keamanan Rumah Menggunakan Sensor PIR (Passive Infrared) Dan SMS Sebagai Notifikasi," Teknik Elektro dan Komputer, vol. 4, no. 6, pp. 10-15, 2015.

[7] Mohd Iqbal and Ahmad Zulfan, "Membangun Sistem Monitoring Keamanan Kerambah Ikan Menggunakan Sensor Gerak dan Fasilitas Smartphone untuk Nelayan di Daerah Perbatasan," in SISFOTEK (Sistem Informasi dan Teknologi Informasi), Padang, 2017, pp. 153-156. 